\title{
Prevalence of Urinary Calcium Oxalate and other Urine Microscopic Parameters among Secondary School Students in Bali, Nigeria
}

\author{
Cletus A. Ukwubile ${ }^{1, *}$, Benedict H. Targema ${ }^{2}$, Livinus I.Tam ${ }^{3}$ \\ ${ }^{* 1}$ Department of Science Laboratory Technology, Biology Unit, Federal Polytechnic Bali, Taraba State, Nigeria \\ ${ }^{2}$ Department of Zoology, Federal University Lafia, Nasarawa State, Nigeria \\ ${ }^{3}$ Sancta Maria Clinic Laboratory (Fhi USAID Affiliate) Bali, Taraba State, Nigeria
}

*Corresponding Author: Cletus A. Ukwubile, Department of Science Laboratory Technology, Biology Unit, Federal Polytechnic Bali, Taraba State,Nigeria.Email: doccletus@yahoo.com

\begin{abstract}
Calcium oxalate is the major cause of human kidney stones in Nigeria and all over the globe. This present research was aimed at investigating the prevalence of urinary calcium oxalate crystals and other urine microscopic parameters among selected secondary schools in Bali, Taraba State Nigeria. 500 urine samples from 10 randomly selected secondary schools were collected from various school students at senior classes, and were analyzed microscopically using a Olympus microscope 4000x. The urine samples were centrifuged at $3000 \mathrm{rpm}$ for $15 \mathrm{~min}$. The supernatant were decanted and the sediments were viewed under microscope using high power objective lens 400x magnification. Results showed that calcium oxalate crystals had the highest prevalence rate of $45 \%$, pus cell was $15 \%$, bilirubin $5 \%$, epithelial cells $5 \%$, flagellated cells was $10 \%, R B C$ was $21 \%$, and triple phosphate was $4 \%$. This increased in prevalence rate was highest in schools with mixed-sexes (Boys and Girls) as compared to same sex schools. The study showed that urinary calcium oxalate crystals were prevalence in most secondary school students in Bali which were associated with food intake and the students social life style.
\end{abstract}

Keywords: Bali, Calcium oxalate, Microscopic parameters, Prevalence, Secondary schools.

\section{INTRODUCTION}

Calcium oxalate crystal is a chemical compound that forms an envelope shaped crystal, known in plants as raphides; a major constituent of human kidney stones (Francesco, 2005).most kidney stones are calcium stones, usually in form of calcium oxalate, oxalate is a naturally occurring substance found in food, some fruit and vegetable, as well as nuts and chocolates, have high oxalate levels. Human liver also produces oxalate, dietary factors, high doses of Vitamin D and several metabolic disorders can increase the concentration of calcium oxalate in urine (Mayo, 2015).Calcium oxalate crystals are the most frequently observe crystals in urine, and 75 $\%$ of renal calculi have calcium oxalate crystals as component.

Calcium oxalate crystal can form at any $\mathrm{pH}$, and have various microscopic morphologies. It is estimated that about half of the oxalate in urine comes from ascorbic acid (Vitamin C) which is a precursor to calcium oxalate. Calcium oxalate crystals are also associated with ethylene glycol ingestion; another oxalate precursor is calcium carbonate $\left(\mathrm{CaCO}_{3}\right)$, the main component of marine shell and egg shells (Kelvin, 2010). The most common metabolic disorder that causes kidney stone in children is hypercalciuria, which causes extra calcium to collect in urine. Other more rare metabolic conditions involve breaking down of oxalate, a substance made in the body found in some foods (Michael, 2012). These condition include hyperoxaluria, too much oxalate in urine oxalis characterized by deposits of oxalate and calcium in the body tissues .

Many plants accumulate calcium oxalate as it has been reported in more than 1000 different genera of plants. The calcium oxalate accumulation is linked to the detoxication of calcium ion in plants. Calcium oxalate is found in rhubarb leaves (Rheum rhabarba L.) in large quantity and in species of oxalis, Areacaceae taro, kiwifruits, tea leaves, agaves, alocasia and spinach in varying amount while insoluble calcium oxalate crystals are found in plant stem, 
root and leaves (Francesco, 2005). Vegetable like okra, parsley, leeks, Swiss chard, collard and quinoa are among the most oxalate-dense vegetables (Assimos, 2015). Calcium oxalate is known to be a major constituent of human kidney stone. Even a small dose of calcium oxalate is enough to cause intense sensations of burning in the mouth and throat, swelling, and choking that could last for up to two weeks, and in greater doses it can cause severe digestive upset, breathing difficulties, coma or even death (Martin et al., 2012).Urinalysis was the first laboratory test performed in medicine and has been used for several years. Urinalysis continues to be a powerful tool in obtaining crucial information for diagnostic purposes in medicine (Echevery et al., 2010). Urinalysis is a test that evaluate a sample of urine, it is use to detect and assess a wide range of disorder, such as urinary tract infections, kidney disease and diabetes. It involves examining the appearance, concentration and content of urine (Mayo, 2015).It is the physical, chemical and microscopic examination of urine. It involves a number of test to detect and measure various compound that passes through the urine, (McPherson and Ben-Ezra, 2013). For example bilirubin pigment in bile may indicate liver diseases. Hemoglobin; iron-containing pigment in red blood cells may indicate injury of the urinary tract, anemia or infection. Cells from the lining of the urinary tract (epithelial cells), crystals may indicate metabolic disease (Stanley, 2007).

This present study was carried out in order to determine the presence of urinary calcium oxalate crystals and other microscopic parameters among secondary school students in Bali.

\section{Materials}

\subsection{Materials}

Microscope, centrifuge, urine sample bottles, glass slides, dropping pipette, ethanol, water bath, etc. All glass wares were sterilized prior to use and after use.

\section{METHODS}

\subsection{Urine Sample Collection}

Urine has a long rich history as a source for measuring health, well-being and remains an important tool for clinical diagnosis. The clinical information obtained from a urine specimen is influenced by the collection method, timing and handling. A vast assortment of collection and transport containers for urine specimens are available. Determining which urine collection method should be used depending on the type of laboratory test ordered. Randomly selected specimens were use for this research since it is the easiest to obtain and it is readily available (NCCLS, 1993).

\subsection{Procedures For Urine Microscopy}

$10 \mathrm{~mL}$ of the urine sample collected were centrifuged at $3000 \mathrm{rpm}$ for $15 \mathrm{~min}$. The supernatant were decanted and the sediments were viewed under microscope using highest power objective lens 400x. The number of calcium oxalate crystals and other microscopic parameters were reported (Siamak, 2014). Photographic shots were made to depicted.

\subsection{Statistical Analysis}

Raw data obtained were expressed as mean \pm SD and percentages. Significance differences between means were compared using one-way analysis of variance (One-way ANOVA). Statically significance was achieved at $\mathrm{p} \leq 0.05$.

\section{RESULTS AND DISCUSSION}

Urine is sometimes supersaturated with calcium oxalate crystals, which means that it contains oxalate crystals that formed spontaneously. The size of these crystals must be controlled to prevent retention in ducts and the eventual development of lithiasis, and this is achieved, in part by specific inhibitors of their growth (Cerinic et al., 1999).

Calcium oxalate $(\mathrm{CaOx})$ exist in monohydrate and dehydrate forms which can be distinguished by the shape of their respective crystals. $\mathrm{CaOx}$ dehydrate crystals are octahedral in shape, and they can grow at any $\mathrm{pH}$ naturally in normal urine. Calcium oxalate monohydrate crystals vary in shape such as prisms, dumbbells, spindles, ovals or picket fences (Martin et al; 2012). In this present study, the shapes of these crystals are mainly octahedral (Plate 1a-d). $\mathrm{CaOx}$ is known to be a major constituents of human kidney stones. Its formation is also one of the toxic effects of ethylene glycol poisoning (Francesco, 2015). The presence of these crystals in urine samples of these secondary school students $(45 \%)$ portrays great danger if not quickly checked (Table 1). The distribution of these crystals in urine samples investigated was age dependent as adult students had the highest percentage prevalence rate. It is possible 
that the social and food habits of the students must have contributed greatly to this anomaly.

Kidney stones typically leave the body in the urine stream, and small stone may pass without causing any symptoms, if stone grew to sufficient size usually at least $3 \mathrm{~mm}$ (0.12in) they can cause blockage of the urethra. In this study, the distribution of octahedral shape $\mathrm{CaOx}$ in urine will unarguably leads to blockage of the urinary tracts. This can lead to pain; most commonly beginning in the flank or lower back and often radiating to the groin. This pain is often known as renal colic and typically comes in waves lasting 20-60min. (Starkey et al., 2014). Crystals found in urine may indicate an abnormality, however they may also be present in normal urine as an artifact (Lean, 2015). There are few relatively health condition that require strict oxalate restriction. These conditions include absorptive hypercalciuria type II, enteric hypercalcuria, and primary hyperoxaluria, Dietary oxalates are usually restricted to $50 \mathrm{mg}$ per day under these circumstances (Freidig, 2011).

The frequency of these crystals and other microscopic parameters in the urine samples of these students calls for urgent medical attention. For example, pus cells in urine signifies that the body is fighting an infection in the lower or upper urinary tract, or it contains dead skin cells, bacteria or white blood cells. Pyuria for instance, mostly exist as result of urinary tract infection (Sharib, 2013). The presence of pus cells in urine which is either caused by urinary tract infection or sexually transmitted infections (UTI or STIs ) have the following identical symptoms fever, abdominal cramps, foul smelling urine, frequent urination, vomiting, irritation, cloudy urine, painful and burning sensation while urinating (Lean, 2015). Our study revealed that, some of these symptoms were experienced by the students. Triple phosphate consist of magnesium ammonium phosphate also called struvite. These parameters can be a normal finding but are also sometimes associated with urinary tract infections.

Bilirubin is not presence in the urine of normal healthy individuals. It is a waste product that is produced by the liver from the hemoglobin of red blood cells that are removed from circulation. The presence of bilirubin in urine is an early indicator of liver diseases. The student revealed that most of the students had a rare presence of this parameter with percentage of
$5.0 \%$ (Table 1). The high presence of flagellated cells in the urine samples suggested one infection or the other since flagellates such as Girdia lamblia often thrives well in the urinary tracts. This may not be different from the result obtained in this study. The presence of intact red blood cell (RBC) in urine usually signifies source of blood loss in the lower part of the urinary tract such as urethra, bladder and ureter because gross haematuria may be related to trauma of the bladder, urethra, tumors or hemorrhage (Melisa, 2014). Students with this in their urine may likely experience this disease if not checked properly. Epithelial cells in urine can provide some information of diagnostic use depending on the type of cells involve and the numbers of the cells (Mayo, 2015). Transition epithelial cells in urine are also common; these cells line the urethra and bladder. From Table 1, although, the occurrence of epithelial cells is low yet their mere presence did not suggest good health conditions in the students. In students with active inflammation, more cells may be shed as a result of irritation.

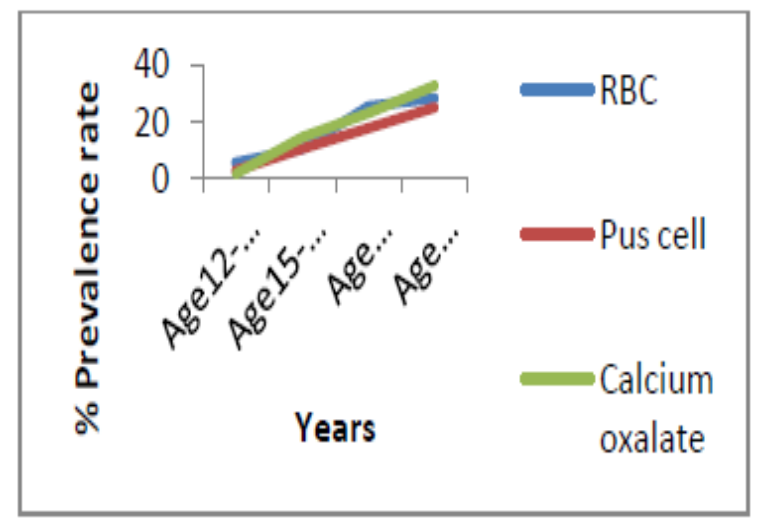

Figure1. Distribution of urinary calcium oxalate, RBC and Pus cell according to ages of studentsSource: Ukwubile et al. (2017).

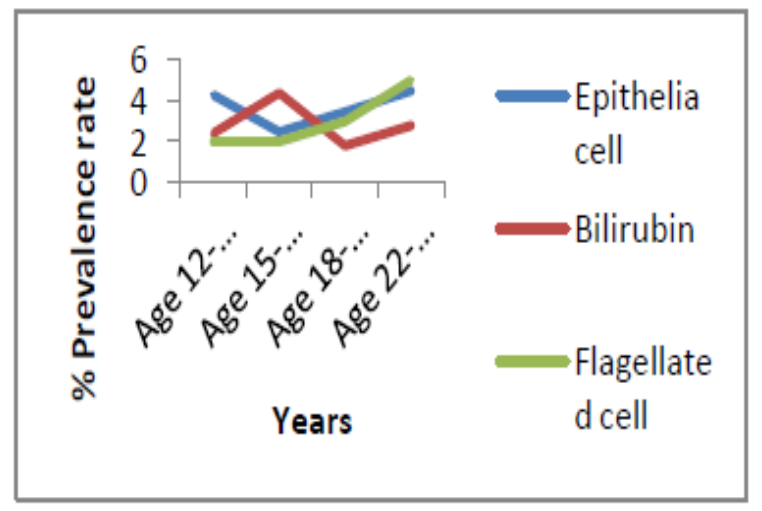

Figure2. Distribution of urinary epithelia cell, Bilirubin and Flagellated cell according to ages of students. Source: Ukwubile et al. (2017). 
Prevalence of Urinary Calcium Oxalate and other Urine Microscopic Parameters among Secondary School Students in Bali, Nigeria

Table1. Microscopic urinary parameters of urine samples collected from schools in Bali

\begin{tabular}{|l|c|l|l|}
\hline \multicolumn{4}{|c|}{ Descriptive Index } \\
\hline Parameter & Frequency & Number/area & $\begin{array}{c}\% \\
\text { Prevalence }\end{array}$ \\
\hline $\begin{array}{l}\text { Calcium } \\
\text { oxalate }\end{array}$ & +++ & $16.2 \pm 0.01 \mathrm{a}$ & 45 \\
\hline $\begin{array}{l}\text { Red blood } \\
\text { cell }\end{array}$ & +++ & $12.1 \pm 0.01 \mathrm{a}$ & 21 \\
\hline Pus cell & ++ & $10.1 \pm 0.02$ & 15 \\
\hline Bilirubin & + & $3.1 \pm 0.1 \mathrm{~b}$ & 5.0 \\
\hline $\begin{array}{l}\text { Flagellated } \\
\text { cell }\end{array}$ & ++ & $13.2 \pm 0.01 \mathrm{a}$ & 10 \\
\hline $\begin{array}{l}\text { Triple } \\
\text { phosphate }\end{array}$ & + & $2.5 \pm 0.1 \mathrm{~b}$ & 4.0 \\
\hline $\begin{array}{l}\text { Epithelial } \\
\text { cells }\end{array}$ & + & $2.7 \pm 0.1 \mathrm{~b}$ & 5.0 \\
\hline
\end{tabular}

$+++=$ highly present,$++=$ moderately present,$+=$ rarely present, numbers followed by the same alphabets are not statistically different at $p \leq 0.05$ (oneway ANOVA), $n=500, N=10$. Results are mean \pm SD of population mean.

Source: Ukwubile et al. (2017).

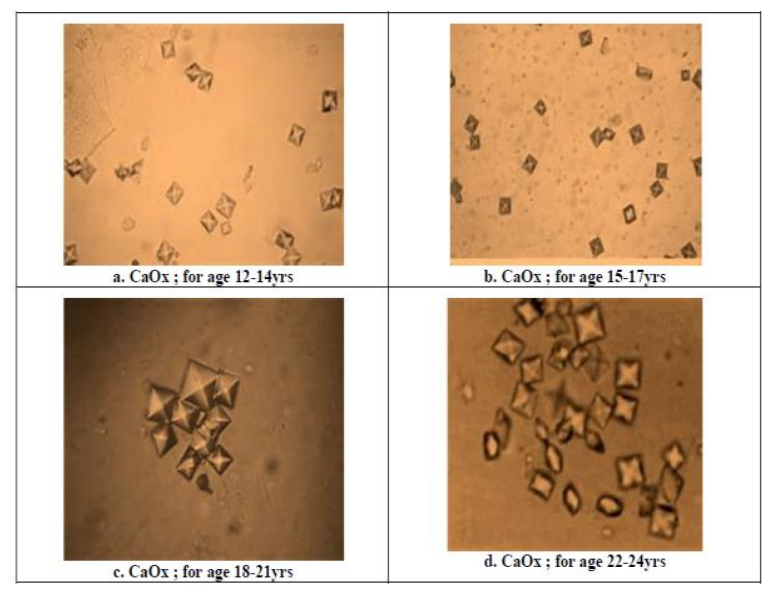

Plate1. Calcium oxalate ( $\mathrm{CaOx}$ ) crystals images as seen under the microscope (400x) Source: Ukwubile et al. (2107)

\section{CONCLUSION}

Our study showed that most of the urine samples collected from secondary school students in Bali has high level of calcium oxalate crystals and other urine microscopic parameters which may be an indicative feature for one infectious disease or the other. However, in this study, it is recommended that students as well as persons with high level of calcium oxalate crystals in their urine should reduce the rate of consumption of oxalate rich foods such as spinach , and they should take much fluid(water) each day as this will help to dissolve the crystals in urines.

\section{ETHICAL CONSIDERATION}

The authors followed strictly the guidelines governing patient's health status confidentiality as advocated by the Nigerian Medical Association (NMA).

\section{ACKNOWLEGEMENT}

The authors are very grateful to the management, staff and the volunteered students of the secondary schools whose urine samples were used in this study.

\section{REFEENCES}

[1] Assimos, A.G.(2015). Bilirubin reductase a major bilirubin excretion. Science, 208 (440): 145-151.

[2] Cerinic, S.T., and Cavaliar, W.F. (1999). Zooflagellates Phylogeny and Classification. 37 (11): 10-29.

[3] Echevery, G., Abdul, H.A., and Mayowa, A.A. (2010). Introduction to urinalysis in historical perspectives and clinical application. Methods in Molecular Biology. 641:112-120.

[4] Francesco, V.R. (2015). Calcium oxalate in plants, formation andfunctions. Annual Review in Plant Biology, 56: 41-71.

[5] Freidig, D.M. (2011). Episodic gross haematuria in association with allergy symptoms in a child. Clinical Nephrology ,58(5): 389-392.

[6] Kevin, F. (2010). Urine calcium laboratory measurement and clinical utility. American Society for Clinical Pathology, 41 (11): 683686.

[7] Lean, M. (2015). Effects of calcium and magnesium on urinary oxalate excretion after oxalate loads, Journal of urology,23(2):43-51.

[8] Martin, G., Matteo, G., Daniel, B., Jacob, Z., and Guillaum, C., (2012). Association between serum total bilirubin levels and functional dependence in the elderly. Internal Medicine Journal, 42(11): 119-207.

[9] Mayo, F.K. (2015). Foundation for Medical Education and Research. Mayo Family Health. 4:56.

[10] McPherson, R.A., and Ben, E.J. (2013). Microscopic examination of urine in clinical diagnosis and management: 35-42.

[11] Michael, L. (2012). The truth about oxalate. Answers to frequently ask questions. Medicine Online. www.mediconline.com

[12] Melisa, D.S. (2014). Ureteropelvic junction obstruction with concurrent renal pelvic calculi in pediatric patients a long term follow up. Intl Journal of endocrinology, 34(2):56- 60.

[13] NCCLS (1993). Urinalysis Collection and Transportation. 12: Pp.45. 
Prevalence of Urinary Calcium Oxalate and other Urine Microscopic Parameters among Secondary School Students in Bali, Nigeria

[14] Sharib, C.W. (2013). Renal Calculus in children. Journal of urology, 107(2):306-307.

[15] Siamaki, A.H. (2014). A short guide to common heterotrophic flagellates of fresh water habitat based on the morphology of living organisms. Protists, 164 (6): 842-860.

[16] Stanley, C.G.(2007). Bladder varices rare cause of painless haematuria in idiophatic retroperitoneal fibrosis. Journal of urology ,73(1): 58-9.

[17] Starkey, C., Jones, J. M., and Lee, D.W. (2014). Animal pigment bilirubin discovered in plants. Journal of the American chemical society, 131 (8): 28-30.

Citation Cletus A. Ukwubile, Benedict H. Targema, \& Livinus I.Tam. Prevalence of Urinary Calcium Oxalate and other Urine Microscopic Parameters among Secondary School Students in Bali, Nigeria. ARC Journal of Urology. 2017; 2(4):17-21. doi: dx.doi.org/10.20431/2456-060X.0204004.

Copyright: (C) 2017 Authors. This is an open-access article distributed under the terms of the Creative Commons Attribution License, which permits unrestricted use, distribution, and reproduction in any medium, provided the original author and source are credited. 